\title{
Efficacy and safety of silodosin, vardenafil versus silodosin in combination with vardenafil as a medical expulsive therapy for distal ureteric stones: a prospective randomized double-blind study
}

Mohamed Samir ${ }^{*} \mathbb{D}$, Hossam Elawady and Mohamed Hasan

\begin{abstract}
Background: Urolithiasis is considered one of the most common diseases in urological practice. Its prevalence is about 1\% to 15\% with 30 years old as the peak age of incidence. Medical expulsive therapy (MET) has been used as a conservative treatment for patients with ureteral stones. Nitrergic fibers have been identified to have a relaxant effect on the distal ureteral smooth musculature. The objective of our study was to evaluate the efficacy and safety of the combination of silodosin and vardenafil as a medical expulsive therapy in comparison with each drug alone.

Methods: One hundred and two male patients with uncomplicated distal ureteric stone 6-10 mm were enrolled in the study. The patients were randomly divided into 3 equal groups, and each one consists of 34 patients. Group I received silodosin $8 \mathrm{mg}$ once daily, group II vardenafil $5 \mathrm{mg}$ once daily and group III combination of silodosin $8 \mathrm{mg}$ and vardenafil $5 \mathrm{mg}$ once daily. The treatment was given for all the patients until stone expulsion or a maximum of 4 weeks. The primary endpoint was the stone expulsion rate, and the secondary endpoints were time to stone expulsion, number of hospital visits for pain, amount of analgesic required and side effects associated with MET.

Results: Our study showed that the stone expulsion rate was higher in combination $=90.0 \%$ than silodosin $=76.7 \%$ and vardenafil groups $=60.0 \%(P=0.025)$, the time to stone expulsion was significantly shorter in combination $=11.23 \pm 3.14$ than silodosin $=12.50 \pm 1.66$ and vardenafil groups $14.67 \pm 1.24$ days $(P<0.01)$, the number of hospital visits for pain was statistically significant between the three groups (silodosin $1.35 \pm 0.9$, vardenafil $1.65 \pm 1.09$ and combination groups $1.02 \pm 0.80)(P=0.038)$ and lesser amount of analgesic required in combination $313.6 \pm 2.85 .5$ than silodosin $613.44 \pm 483.62$ and vardenafil groups $716.97 \pm 685.3(P=0.008)$. There was no significant difference among the studied groups as regards the drugs side effects except for retrograde ejaculation (silodosin and combination $=86.7 \%$ vs vardenafil groups $=0.0 \%)(P<0.05)$ and increased erection (combination $=26.7 \%$, vardenafil $=23.3 \%$ and silodosin groups $=0 \%)(P=0.010)$.
\end{abstract}

Conclusion: The prescription of vardenafil in combination with silodosin is safe and more effective than silodosin or vardenafil alone as a MET.

Keywords: Silodosin, Vardenafil, Medical expulsive therapy, Ureteric stones

*Correspondence: m.samir-84@hotmail.com

Department of Urology, Ain Shams University Hospitals, Cairo, Egypt 


\section{Background}

Urolithiasis is considered one of the most common diseases in urological practice. The prevalence about $1 \%$ to $15 \%$ with 30 years is the peak age of incidence. Male-tofemale ratio is $2-3$ to 1 . Ureteral stones represent $20 \%$ of all urolithiasis, and about $70 \%$ of ureteral stones are in the distal ureter [1].

Ureteral stones lead to ureteral spasms which interfere with stone expulsion. Therefore, trials to reduce these spasms without affecting the normal peristaltic activity have been made to aid stone expulsion. Medical expulsive therapy (MET) especially using $\alpha$-blockers has been used as conservative treatment for patients with ureteral stones [2].

The $\alpha$ receptors have 2 subtypes: $\alpha 1$ and $\alpha 2$. $\alpha 1$ receptors are further classified into 3 subtypes of $\alpha-1 \mathrm{~A}, \alpha-1 \mathrm{~B}$ and $\alpha-1 \mathrm{D}, \alpha-1 \mathrm{D}>\alpha-1 \mathrm{~A}>\alpha-1 \mathrm{~B}$ in their distribution in the ureter. $\alpha 1$-adrenoceptors stimulation leads to increase in the ureteric peristalsis frequency and the power of ureteric contractions. Therefore, blockage of these receptors using silodosin reduces ureteral tone and decreases peristaltic force and frequency, leading to lowering of ureteral intra-luminal pressure which increases the stone passage chance [3]. Silodosin is a more selective $\alpha-1 \mathrm{~A}$ adrenoceptor blocker with a better stone expulsion rate than tamsulosin [4].

Nitrergic fibers have been identified to have a relaxant effect on the distal ureteral smooth musculature [5]. Recently, investigators focused on how blockade of this nitric oxide pathway can be effectively carried out in clinical practice until phosphodiesterase-5 inhibitors (PDE5Is) existed [6, 7]. Vardenafil is a PDE5 inhibitor. Gratzke et al. reported that vardenafil is more potent in ureteral muscles relaxation than sildenafil and tadalafil [8].

Previous study had demonstrated that the combination of silodosin and tadalafil is more potent than either drug alone for the treatment of distal ureteric stones [1], but no study has been reported using vardenafil and silodosin in combination for the treatment of distal ureteric stones. Therefore, the efficacy of this combination was evaluated in comparison with the use of each drug alone.

\section{Methods}

From May 2019 to November 2019, this prospective study was carried out at a single tertiary care hospital. Approval of the ethical committee of our institution was obtained before the start of the study. The inclusion criteria included male patients aged between 18 and 55 years with single radiopaque ureteric stone located below the sacroiliac joint ranging in size between 6 and $10 \mathrm{~mm}$. Exclusion criteria were single kidney, bilateral ureteric stones, severe intractable pain, impairment of renal function, urinary tract infection (UTI), severe hydronephrosis, any urologic anomalies and previous history of ureteral surgery. Also, patients on concomitant treatment with nitrates or calcium channel blockers or with severe hepatic impairment were excluded.

A total of 267 patients with distal ureteric stones were assessed for eligibility to enter the study. One hundred and sixty-five patients were excluded for different reasons (not meeting inclusion criteria 70 patients, refused to participate 54 patients and for other reasons 41 patients) as in Fig. 1. One hundred and two patients who fulfilled the inclusion criteria were enrolled in the study. Informed written consent was obtained from all the patients after explanation of the study procedures and the possible side effects. The patients were randomly divided into 3 equal groups, and each one consists of 34 patients using closed envelope method. Group I received silodosin $8 \mathrm{mg}$ once daily, group II vardenafil $5 \mathrm{mg}$ once daily and group III combination of silodosin $8 \mathrm{mg}$ and vardenafil $5 \mathrm{mg}$ once daily. The treatment was given for all the patients until stone expulsion or a maximum of 4 weeks. Patients were assessed by history taking, general examination, serum creatinine, urine analysis, urine culture, KUB (kidney, ureter and bladder X-ray) and non-enhanced spiral CT. Patients were advised to take diclofenac $75 \mathrm{mg}$ tablet orally during pain episodes along with the allocated drug. Patients were instructed to filter their urine to detect any passed stones. Our study was planned as a double-blind study, and both the investigators and the participants were unaware of the type of the treatment received.

Follow-up was performed weekly by history taking (stone passage, number of hospital visits for pain, total analgesia required and side effects associated with MET) and ultrasonography until spontaneous passage of the stone or stoppage of MET after 4 weeks. The primary endpoint was the stone expulsion rate, and the secondary endpoints were time to stone expulsion, number of hospital visits for pain, amount of analgesic required and side effects associated with MET.

Data was collected, revised, coded and entered into the Statistical Package for Social Science (IBM SPSS) version 23. Normality of data was checked using Kolmogorov-Smirnov test for normality. The comparison between groups regarding qualitative data was done by Chi-square test. The comparison between more than two independent groups with quantitative data and parametric distribution was done by one-way ANOVA test. $\mathrm{P}$ value is considered significant if $<0.05$.

\section{Results}

There was no statistically significant difference between the groups for patient's age, stone site and stone size $(P>0.05)$ as in Table 1. 


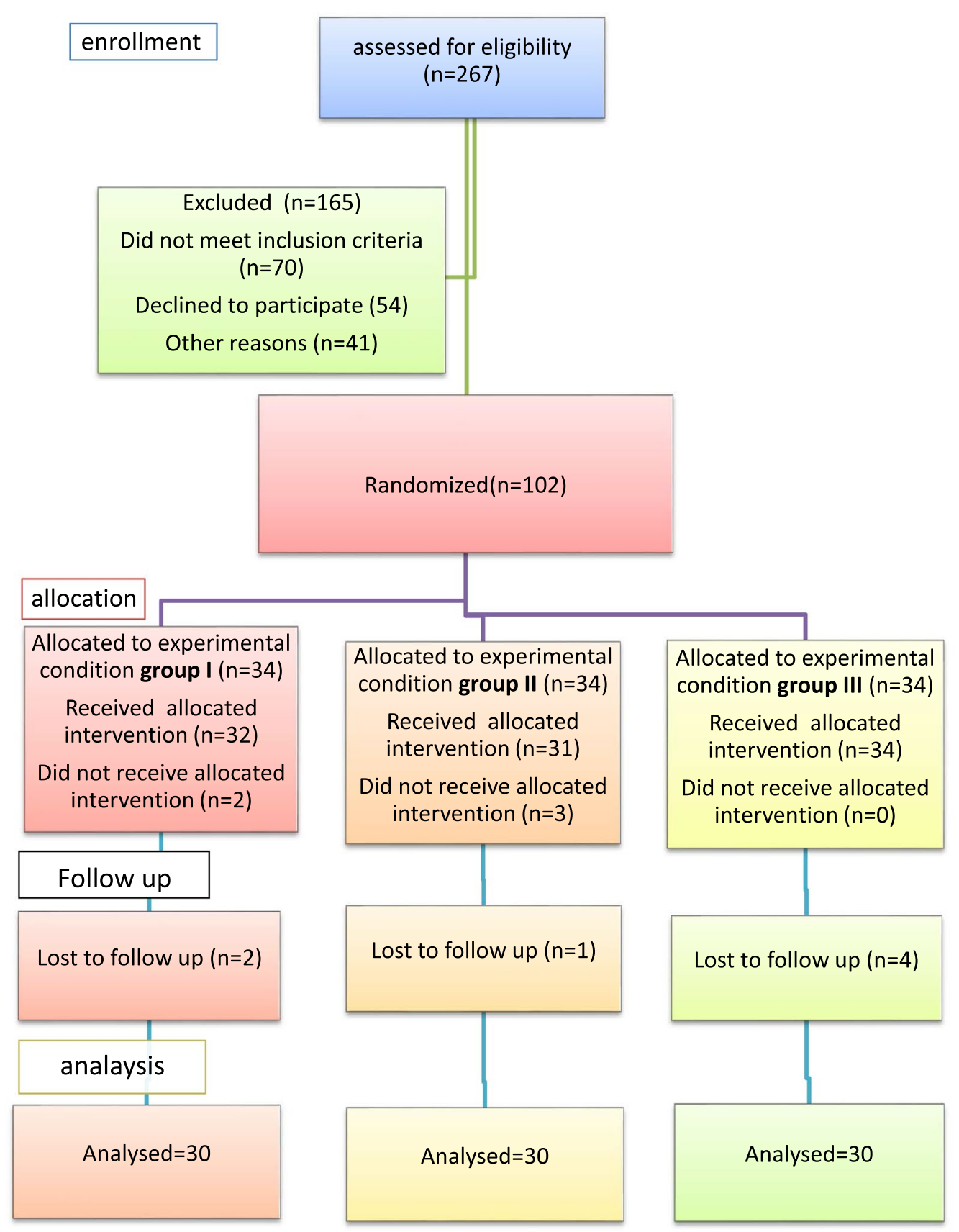

Fig. 1 Consort flowchart

The stone expulsion rate was significantly higher in combination than silodosin and vardenafil groups $(P=0.025)$, the time to stone expulsion was significantly shorter in combination than silodosin and vardenafil groups $(P<0.01)$, the number of hospital visits for pain was significantly lesser in combination than silodosin and vardenafil groups $(P=0.038)$ and lesser amount of analgesic required in combination than silodosin and vardenafil groups $(P=0.008)$ as in Table 2 .

There was no significant difference among the studied groups regarding headache $(P=0.749)$, dizziness $(P=0.856)$, orthostatic hypotension $(P=0.585)$. However, incidence of retrograde ejaculation was significantly higher in silodosin and combination groups than 
vardenafil group $(P<0.05)$ and increased erection was significantly higher in combination and vardenafil groups than silodosin group $(P=0.010)$ as in Table 3 .

\section{Discussion}

The primary benefit of conservative approach in the management of ureteral calculi is minimal patient morbidity. Conservative medical treatment is usually indicated in the treatment of uncomplicated distal ureteral stones of
6-10 $\mathrm{mm}$ size as these stones have lower chances to pass spontaneously [9].

A great advance in the MET has been achieved with the use of $\alpha-1$ adrenoreceptor antagonists to treat these stones by accelerating stone passage through inducing relaxation of distal ureteral smooth muscles [10]. The $\alpha-1$ adrenoreceptor antagonists act by inhibiting basal muscular tone, uncoordinated hyperperistaltic wave frequency and ureteral contractions of distal ureter leading

Table 1 Comparison between groups according to demographic data

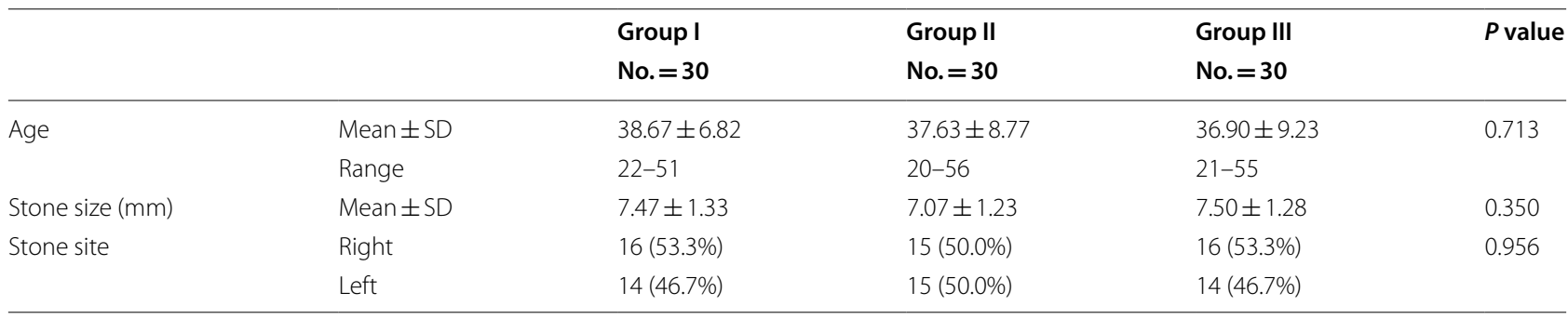

Table 2 Comparison between 3 groups regarding stone expulsion rate, stone expulsion time, number of hospital visits for pain and amount of analgesic required

\begin{tabular}{|c|c|c|c|c|c|}
\hline & & $\begin{array}{l}\text { Group I } \\
\text { No. }=30\end{array}$ & $\begin{array}{l}\text { Group II } \\
\text { No. }=30\end{array}$ & $\begin{array}{l}\text { Group III } \\
\text { No. }=30\end{array}$ & $P$ value \\
\hline \multirow[t]{2}{*}{ Stone expulsion rate } & No & $7(23.3 \%)$ & $12(40.0 \%)$ & $3(10.0 \%)$ & 0.025 \\
\hline & Yes & $23(76.7 \%)$ & $18(60.0 \%)$ & $27(90.0 \%)$ & \\
\hline \multirow[t]{2}{*}{ Stone expulsion time (days) } & Mean $\pm S D$ & $12.50 \pm 1.66$ & $14.67 \pm 1.24$ & $11.23 \pm 3.14$ & $<0.01$ \\
\hline & Range & $10-16$ & $12-18$ & $7-18$ & \\
\hline \multirow[t]{2}{*}{ Number of hospital visit for pain } & Mean \pm SD & $1.35 \pm 0.9$ & $1.65 \pm 1.09$ & $1.02 \pm 0.80$ & 0.038 \\
\hline & Range & $0-4$ & $0-5$ & $0-3$ & \\
\hline \multirow[t]{2}{*}{ Amount of analgesic required (mg) } & Mean $\pm S D$ & $613.44 \pm 483.62$ & $716.97 \pm 685.3$ & $313.6 \pm 285.5$ & 0.008 \\
\hline & Range & $0-1800$ & $0-3000$ & $0-3000$ & \\
\hline
\end{tabular}

Table 3 Comparison between the groups according to common complications

\begin{tabular}{|c|c|c|c|c|c|c|c|c|}
\hline & & \multicolumn{2}{|c|}{ Group I } & \multicolumn{2}{|c|}{ Group II } & \multicolumn{2}{|c|}{ Group III } & \multirow[t]{2}{*}{$P$ value } \\
\hline & & No. & $\%$ & No. & $\%$ & No. & $\%$ & \\
\hline \multirow[t]{2}{*}{ Headache } & No & 26 & 86.7 & 27 & 90.0 & 25 & 83.3 & 0.749 \\
\hline & Yes & 4 & 13.3 & 3 & 10.0 & 5 & 16.7 & \\
\hline \multirow[t]{2}{*}{ Dizziness } & No & 28 & 93.3 & 27 & 90.0 & 28 & 93.3 & 0.856 \\
\hline & Yes & 2 & 6.7 & 3 & 10.0 & 2 & 6.7 & \\
\hline \multirow[t]{2}{*}{ Orthostatic hypotension } & No & 29 & 96.7 & 27 & 90.0 & 28 & 93.3 & 0.585 \\
\hline & Yes & 1 & 3.3 & 3 & 10.0 & 2 & 6.7 & \\
\hline \multirow[t]{2}{*}{ Retrograde ejaculation } & No & 4 & 13.3 & 30 & 100.0 & 4 & 13.3 & 0.000 \\
\hline & Yes & 26 & 86.7 & 0 & 0.0 & 26 & 86.7 & \\
\hline \multirow[t]{2}{*}{ Increased erection } & No & 30 & 100.0 & 23 & 76.7 & 22 & 73.3 & 0.010 \\
\hline & Yes & 0 & 0.0 & 7 & 23.3 & 8 & 26.7 & \\
\hline
\end{tabular}


to relaxation of ureteral smooth muscles with subsequent ureteral lumen dilatation which results in increase in the rate of stone expulsion [11].

Recently, PDE5 inhibitors were reported to act on the nitric oxide (NO)/cyclic guanosine monophosphate (cGMP) pathway in the smooth muscles, resulting in accumulation of cGMP, resulting in ureteral smooth muscle relaxation. So, PDE5 inhibitors are potentially able to facilitate stone expulsion [8]. Despite having a well-established role in erectile dysfunction (ED) and benign prostatic hyperplasia (BPH), the use of PDE5 inhibitor for MET is in the preliminary stage.

In our study, we found that the stone expulsion rate was significantly higher in combination than silodosin and vardenafil groups $(90.0 \%, 76.7 \%$ and $60.0 \%$, respectively) $(P=0.025)$. Like our results, Girish et al. [12] reported that there was a higher expulsion rate $76 \%$ in combination therapy group compared to $73 \%$ in tadalafil group and $70 \%$ in tamsulosin group. There was an increase in expulsion rate in patients with combination therapy, though statistical significance could not be demonstrated. Kumar et al. [6] reported that the stone expulsion rates for tamsulosin, silodosin and tadalafil were $64.4 \%, 83.3 \%$ and $66.7 \%$, respectively, but there was no significant difference between the tamsulosin and tadalafil groups $(P=0.875)$. Abhishek et al. [13] reported that the stone expulsion rate was $58 \%$ for placebo group, $80 \%$ for tadalafil group and $74 \%$ for tamsulosin group. Tadalafil was superior to placebo in stone expulsion rate $(P=0.017)$.

The reason for a higher stone expulsion rate in combination group can be explained by the fact the combination of vardenafil and silodosin with different mechanisms of action. Silodosin acts as $\alpha-1 \mathrm{~A}$ adrenoceptor blocker, whereas vardenafil acts as PDE5 inhibitor, and thus, the combination of the two drugs may further help in increase in stone expulsion [1].

In this study, we found that the mean stone expulsion time was significantly shorter in combination than silodosin and vardenafil groups (11.23 \pm 3.14 , $12.50 \pm 1.66$ and $14.67 \pm 1.24$ days, respectively, $P<0.01)$. Similarly, Girish et al. [12] concluded that the time to expulsion was lesser in combination therapy compared to tamsulosin and tadalafil groups, but this difference was not statistically significant (3.61, 4.05 and 4.14 days, respectively, $P=0.545$ ). Kc et al. [14] showed that the mean stone expulsion time was lower in tadalafil ( $8.08 \pm 3.3$ days) than in tamsulosin groups $(9.64 \pm 3.8$ days), but also this difference was not statistically significant $(P=0.094)$. However, Goyal et al. [15] reported that the mean expulsion time was lower for tamsulosin (9.38 \pm 6.66 days) than for tadalafil groups (9.61 \pm 7.47 days), but this difference was not significant $(P=0.78)$. In contrast, Puvvada et al.
[16] reported that the mean time for stone expulsion in tadalafil was $14.7 \pm 3.8$ days and in tamsulosin groups was $16.8 \pm 4.5$ days. The time was significantly shorter in tadalafil group than tamsulosin group $(P=0.0021)$.

We found that the number of hospital visits for pain was statistically significant between groups (silodo$\sin =1.35 \pm 0.9$, vardenafil $=1.65 \pm 1.09$ and combination groups $=1.02 \pm 0.80) \quad(P=0.038)$ and the amount of analgesic of intake for pain was significantly the least in combination ( $313.6 \pm 2.85 .5)$, followed by silodosin (613.44 \pm 483.62$)$, and then vardenafil groups $(716.97 \pm 685.3 \mathrm{mg}$ of diclofenac sodium $)(P=0.008)$. Similarly, Rahman MJ et al. [1] found that silodosin plus tadalafil had significantly fewer pain episodes than silodosin and tadalafil alone $(P<0.001)$. Also, Jayant et al. [17] showed significantly fewer episodes of pain with tadalafil plus tamsulosin as compared to tamsulosin alone. This may be explained by the different mechanism of action of the two drugs. Silodosin blocks the C fibers, and tadalafil acts through decreasing the frequency and amplitude of ureteric phasic contractions and decreases the intra-luminal ureteric pressure, and so reduces pain episodes [1].

In our study, we found that there were no significant differences among the studied groups regarding headache, dizziness and orthostatic hypotension $(P>0.05)$. This can be explained by the young age of the studied population. However, there was a highly significant difference among the studied groups regarding retrograde ejaculation ( silodosin and combination $=86.7 \%$ vs vardenafil groups $=0.0 \%)(P<0.05)$ and the increased erection was significantly higher in group III (vardenafil plus silodosin) (0.010). This can be an advantage in patients with lower ureteric stones and ED. However, all these side effects were mild and well tolerated. No patients were excluded from the study because of occurrence of side effects. Similarly, Girish et al. [12] reported that there were no serious adverse effects noted and Goyal et al. [15] showed that no statistical difference was detected for adverse drug effects except for retrograde ejaculation, which was significantly higher in tamsulosin group $(P<0.001)$. Again, Kc et al. [14] reported that there were no serious adverse effects. Although the overall incidence of dugs side effects was higher with tadalafil, this difference was not statistically significant $(14.6 \%$ vs. $29.5 \%$, $P=0.099$ ).

The main limitations of our study were the relatively small sample size, and we did not assess the frequency of sexual intercourse which may be related to stone expulsion. However, to best of our knowledge, this is the first randomized study to evaluate the effect of the combination of silodosin plus vardenafil as a MET. Hence, further studies on a larger number of patients will help to 
establish the role of combination silodosin plus vardenafil as a medical expulsive therapy for lower ureteric stones.

\section{Conclusion}

The combination of silodosin and vardenafil significantly increases the stone expulsion rate and decreases the time to stone expulsion. This combination also significantly decreases the pain episodes without incidence of serious side effects.

\section{Abbreviations}

MET: medical expulsive therapy; PDE5Is: phosphodiesterase-5 inhibitors; UTI: urinary tract infection; KUB: kidney, ureter and bladder X-ray; NO: nitric oxide; CGMP: cyclic guanosine monophosphate; ED: erectile dysfunction; $\mathrm{BPH}$ : benign prostatic hyperplasia.

\section{Acknowledgements}

None.

\section{Authors' contributions}

MS suggested the idea of the study, collected the data and was a major contributor in writing the manuscript. HE revised the manuscript. $\mathrm{MH}$ analyzed and interpreted the patient data. All authors read and approved the final manuscript.

\section{Availability of data and materials}

The datasets used and/or analyzed during the current study are available from the corresponding author on reasonable request.

\section{Ethics approval and consent to participate}

Approval of the ethical committee of Ain Shams University, faculty of medicine was obtained before the start of the study, but the reference number is not available. All patients gave a written informed consent to participate in the study.

\section{Competing interests}

The authors declare that they have no competing interests.

\section{Consent for publication}

Not applicable.

Received: 23 January 2020 Accepted: 2 June 2020

Published online: 21 July 2020

\section{References}

1. Rahman MJ, Faridi MS, Mibang N et al (2017) Comparing tamsulosin, silodosin versus silodosin plus tadalafil as medical expulsive therapy for lower ureteric stones: a randomised trial. Arab J Urol 16(2):245-249
2. Turk C, Petrik A, Sarica K et al (2016) EAU guidelines on interventional treatment for urolithiasis. Eur Urol 69:475-4823

3. Itoh Y, Okada A, Yasui T (2013) Administration of the selective alpha $1 \mathrm{~A}$-adrenoceptor antagonist Silodosin facilitates expulsion of size 5-10 mm distal ureteral stones, as compared to control. Int Urol Nephrol 45:675-678

4. Elgalaly H, Sakr A, Fawzi A et al (2016) Silodosin vs tamsulosin in the management of distal ureteric stones: a prospective randomised study. Arab J Urol 14:12-17

5. Yucel S, Baskin LS (2003) Neuroanatomy of the ureterovesical junction: clinical implications. J Urol 170:945-948

6. Kumar S, Jayant K, Agrawal MM et al (2015) Role of tamsulosin, tadalafil, and silodosin as the medical expulsive therapy in lower ureteric stone: a randomized trial (a pilot study). Urology 85:59-63

7. Shokeir AA, Tharwat M, Abolazm AE et al (2016) Sildenafil citrate as a medical expulsive therapy for distal ureteric stones: a randomised double-blind placebo-controlled study. Arab J Urol 14:1-6

8. Gratzke C, Uckert S, Kedia G (2007) In vitro effects of PDE5 inhibitors sildenafil, vardenafil and tadalafil on isolated human ureteral smooth muscle: a basic research approach. Urol Res 35:49-54

9. Seitz C, Liatsikos E, Porpiglia F et al (2009) Medical therapy to facilitate the passage of stones: What is the evidence? Eur Urol 56:455-471

10. Cervenakov I, Fillo J, Mardiak J et al (2002) Speedy elimination of ureterolithiasis in lower part of ureters with the alpha 1-blocker tamsulosin. Int Urol Nephrol 34:25-29

11. Porpiglia F, Vaccino D, Billia M et al (2006) Corticosteroids and tamsulosin in the medical expulsive therapy for symptomatic distal ureter stones: single drug or association? Eur Urol 50(2):339-344

12. Girish TD, Raza SZ, Kumar RV et al (2016) The role of tadalafil and tamsulosin alone and in combination therapy in lower ureteric stone expulsion. J Evol Med Dent Sci 5(77):5746-5749

13. Abhishek L, Shashikant M, Arvind G et al (2019) Comparison of tadalafil and tamsulosin in medical expulsive therapy for ureteric calculus: prospective, randomized, placebo-controlled study. IJMHS 9(2):294-298

14. Hb KC, Shrestha A, Acharya GB et al (2016) Tamsulosin versus tadalafil as a medical expulsive therapy for distal ureteral stones: a prospective randomized study. Investig Clin Urol 57(5):351-356

15. Goyal SK, Singh V, Pandey H et al (2018) Comparative efficacy of tamsulosin versus tadalafil as medical expulsive therapy for distal ureteric stones. Urol Ann 10(1):82-86

16. Puvvada S, Mylarappa P, Aggarwal Ket al (2016) Comparative efficacy of tadalafil versus tamsulosin as the medical expulsive therapy in lower ureteric stone: a prospective randomized trial. Cent Eur J Urol 69(2):178-182

17. Jayant K, Agrawal R, Agrawal S (2014) Tamsulosin versus tamsulosin plus tadalafil as medical expulsive therapy for lower ureteric stones: a randomized controlled trial. Int J Urol 21:1012-1015

\section{Publisher's Note}

Springer Nature remains neutral with regard to jurisdictional claims in published maps and institutional affiliations.

\section{Submit your manuscript to a SpringerOpen ${ }^{\circ}$ journal and benefit from:}

- Convenient online submission

- Rigorous peer review

- Open access: articles freely available online

- High visibility within the field

- Retaining the copyright to your article

Submit your next manuscript at springeropen.com 